\title{
Updates on Direct Oral Anticoagulants in the Management of Atrial Fibrillation
}

\author{
Judy WM Cheng1,2 \\ 1. Department of Pharmacy Practice, Massachusetts College of Pharmacy and Health Sciences (MCPHS) University, Boston, MA, USA;
}

2. Department of Pharmacy, Brigham and Women's Hospital, Boston, MA, USA

DOI: https://doi.org/10.17925/EJAE.2019.5.1.24

$\mathrm{D}$ rect thrombin inhibitor (dabigatran) and factor Xa inhibitors (apixaban, edoxaban, rivaroxaban) have been established as safe and effective alternatives to warfarin for stroke prevention in patients with non-valvular atrial fibrillation (AF). Direct oral anticoagulants (DOACS) have gained popularity since becoming available on the market, due to their lack of need for laboratory monitoring and relatively few drug and food interactions. However, while warfarin has extensive clinical evidence supporting its use in AF patient populations with various comorbidities, there is limited evidence in the use of DOACs in many AF patient subpopulations. Results available to date suggested that DOACs are generally well tolerated across a wide spectrum of patients with AF, including those with renal dysfunction and valvular heart disease. The use of DOACs in patients with a mechanical heart valve is not recommended due to increased risk of thromboembolic events. In patients with AF and coronary stents, the use of DOACs in addition to dual antiplatelet therapy increase bleeding. However, removal of aspirin from the regimen appeared to maintain equivalent efficacy for preventing cardiovascular events without increased risk of bleeding. Furthermore, DOACs can be safely used in peri-cardioversion and peri-catheter ablation to prevent thromboembolic events. Reversal agents are now available should major bleeding occur; this will continue to expand the use of DOACs. Future research will continue to explore the use of DOACs in other AF special populations, such as pregnancy, and in other coagulation disorders, where warfarin is the current preferred agent.

\section{Keywords}

Direct oral anticoagulants, atrial fibrillation

Disclosures: Judy WM Cheng has nothing to declare in relation to this article.

Review Process: Double-blind peer review.

Compliance with Ethics: This study involves a review of the literature and did not involve any studies with human or animal subjects performed by any of the authors.

Authorship: The named author meets the criteria of the International Committee of Medical Journal Editors for authorship for this manuscript, takes responsibility for the integrity of the work as a whole and has given final approval for the version to be published.

Received: 25 September 2018

Accepted: 28 November 2018

Citation: European Journal of Arrhythmia \&

Electrophysiology. 2019;5(1):24-9

Corresponding Author: Judy Cheng, 179 Longwood Avenue, Boston, MA 02115 US. E: judy.cheng@mcphs.edu

Support: No funding was received for

the publication of this article.
Anticoagulants play a significant role in stroke prevention caused by atrial fibrillation (AF), which is the most common cardiac arrhythmia. It is estimated that more than five million people in the USA and more than eight million people in Europe have AF. For many years, vitamin K antagonists, such as warfarin, were the only oral anticoagulant for stroke prevention in AF. However, variability in dose response among patients, their slow onset and offset of action, requirement for frequent laboratory monitoring and extensive drug and food interactions make their use complicated. ${ }^{2}$ Since 2010, four other oral anticoagulants have been approved for prevention of stroke in patients with AF. Dabigatran, a direct thrombin inhibitor, and apixaban, edoxaban and rivaroxaban, all factor Xa inhibitors, collectively called direct oral anticoagulants (DOACs), have all been demonstrated to be at least non-inferior to warfarin in terms of stroke prevention and reduction in certain major bleeding events such as intra-cranial haemorrhage..-6 DOACs have gained popularity due to the lack of frequent laboratory monitoring required and relatively few drug and food interactions, compared with warfarin. However, warfarin is far from becoming an obsolete therapy due to extensive evidence and clinical experience in its use in patients with AF and various comorbidities. There is still limited evidence in the use of DOACs in many AF patient subpopulations, such as patients with AF and concurrent renal dysfunction, patients with valvular heart disease or valve replacement, patients with AF undergoing electrical cardioversion or radiofrequency ablation, and patients with AF who undergo percutaneous coronary intervention (PCI). This article reviews published evidence in the use of DOACs in stroke prevention in AF, focusing on updates in their use in special populations since the publication of the four original landmark comparative trials to warfarin.

\section{Study selection and data extraction}

Peer-reviewed clinical trials, review articles and relevant treatment guidelines were identified from the MEDLINE and Current Content databases (both from 1 January 1966 to 31 August 2018) using the search terms 'apixaban', 'dabigatran', 'edoxaban', 'rivaroxaban' and 'atrial fibrillation'. Citations from available articles were also reviewed for additional references. Thirty-seven studies are included for review and discussion. Table 1 summarises the results of these studies.-29

\section{Clinical efficacy in non-valvular atrial fibrillation}

The clinical efficacy of all DOACs in terms of stroke prevention in AF was established in large-scale phase III randomised, active control (compared with warfarin) trials in patients specifically with non-valvular AF. The RE-LY (Randomized Evaluation of Long Term Anticoagulant Therapy) trial was a non-inferiority, double-blind, randomised controlled study that compared 
Table 1: Summary overview of direct oral anticoagulants in special populations

\begin{tabular}{|c|c|c|c|c|}
\hline Patient population & Dabigatran & Apixaban & Rivaroxaban & Edoxaban \\
\hline Renal dysfunction ${ }^{7-10}$ & $\begin{array}{l}\text { Not preferred over other agents } \\
\text { if } \mathrm{CrCl}<50 \mathrm{~mL} / \mathrm{min} / \mathrm{m}^{2} \text {; note that } \\
75 \mathrm{mg} \text { twice daily dose approved } \\
\text { for } \mathrm{CrCl} 15-30 \mathrm{~mL} / \mathrm{min} / \mathrm{m}^{2} \text { but no } \\
\text { outcomes data available }\end{array}$ & $\begin{array}{l}\text { Preferred option in renal } \\
\text { impairment; note that dosing } \\
\text { is based on age, weight and } \\
\text { SCR, not CrCl; dose of } 5 \text { mg } \\
\text { twice daily approved for ESRD } \\
\text { on haemodialysis but clinical } \\
\text { outcomes not } \\
\text { evaluated }\end{array}$ & $\begin{array}{l}\text { Increased Gl bleeding if } \mathrm{CrCl} \\
<50 \mathrm{~mL} / \mathrm{min} / \mathrm{m} \text {; dose of } 15 \mathrm{mg} \\
\text { once daily approved for ESRD } \\
\text { on haemodialysis but clinical } \\
\text { outcomes not evaluated }\end{array}$ & $\begin{array}{l}\text { Efficacy appears greatest } \\
\text { in lower GFR categories; } \\
\text { not indicated for } \\
\mathrm{CrCl}>95 \mathrm{~mL} / \mathrm{min} / \mathrm{m}^{2} \text { or } \\
<15 \mathrm{~mL} / \mathrm{min} / \mathrm{m}^{2}\end{array}$ \\
\hline Obesity $^{16,17}$ & $\begin{array}{l}\text { Pharmacokinetic, pharmacodynamic, } \\
\text { and clinical outcomes data are } \\
\text { lacking }\end{array}$ & $\begin{array}{l}\text { Reduced exposure in obesity, } \\
\text { but clinical outcomes data } \\
\text { lacking }\end{array}$ & $\begin{array}{l}\text { Reduced exposure in obesity, } \\
\text { but clinical outcomes data } \\
\text { lacking }\end{array}$ & $\begin{array}{l}\text { Pharmacokinetic, } \\
\text { pharmacodynamic and clinical } \\
\text { outcomes data are lacking }\end{array}$ \\
\hline $\begin{array}{l}\text { Valvular heart } \\
\text { disease }^{18,19}\end{array}$ & $\begin{array}{l}\text { Contraindicated in mechanical heart } \\
\text { valve. } \\
\text { Might be a reasonable alternative to } \\
\text { patients with AF and valvular heart } \\
\text { disease }\end{array}$ & $\begin{array}{l}\text { Contraindicated in mechanical } \\
\text { heart valve. } \\
\text { Might be a reasonable } \\
\text { alternative to patients with AF } \\
\text { and valvular heart disease }\end{array}$ & $\begin{array}{l}\text { Contraindicated in mechanical } \\
\text { heart valve. } \\
\text { Might be a reasonable } \\
\text { alternative to patients with AF } \\
\text { and valvular heart disease }\end{array}$ & $\begin{array}{l}\text { Contraindicated in mechanical } \\
\text { heart valve. } \\
\text { Might be a reasonable } \\
\text { alternative to patients with AF } \\
\text { and valvular heart disease }\end{array}$ \\
\hline Cardioversion $^{15,16-22}$ & $\begin{array}{l}\text { Might be a reasonable alternative to } \\
\text { patients with AF and valvular heart } \\
\text { disease }\end{array}$ & Prospective study ongoing 22 & $\begin{array}{l}\text { Might be a reasonable } \\
\text { alternative to patients with AF } \\
\text { and valvular heart disease }\end{array}$ & $\begin{array}{l}\text { Might be a reasonable } \\
\text { alternative to patients with AF } \\
\text { and valvular heart disease }\end{array}$ \\
\hline Ablation $^{23,24,27}$ & $\begin{array}{l}\text { Might be a reasonable alternative to } \\
\text { patients with AF and valvular heart } \\
\text { disease }\end{array}$ & Prospective study ongoing ${ }^{27}$ & $\begin{array}{l}\text { Might be a reasonable } \\
\text { alternative to patients with AF } \\
\text { and valvular heart disease }\end{array}$ & Prospective study ongoing ${ }^{28}$ \\
\hline $\begin{array}{l}\text { Percutaneous } \\
\text { coronary } \\
\text { intervention } \\
\text { in-5,34 }\end{array}$ & $\begin{array}{l}\text { Dabigatran } 110 \text { mg twice daily } \\
\text { or } 150 \text { mg twice daily plus P } 2 \text { Y } 12 \\
\text { inhibitor without aspirin is preferred } \\
\text { over triple antiplatelet therapy }\end{array}$ & Data lacking & $\begin{array}{l}\text { Rivaroxaban } 15 \text { mg daily or } \\
2.5 \text { mg twice daily plus DAPT } \\
\text { is preferred over } \\
\text { standard-dose triple therapy }\end{array}$ & Data lacking \\
\hline $\begin{array}{l}\text { Transcatheter aortic } \\
\text { valve replacement }{ }^{26}\end{array}$ & Data lacking & $\begin{array}{l}\text { Might be a reasonable } \\
\text { alternative to patients with AF } \\
\text { and valvular heart disease }\end{array}$ & Data lacking & Data lacking \\
\hline
\end{tabular}

$A F=$ atrial fibrillation; $\mathrm{CrCl}=$ creatinine clearance; $D A P T=$ dual antiplatelet therapy; $E S R D=$ end-stage renal disease; GFR = glomerular filtration rate; $G \mathrm{l}=$ gastrointestinal; $\mathrm{sCr}=$ serum creatinine.

dabigatran (110 mg twice daily or $150 \mathrm{mg}$ twice daily) to a warfarin dose adjusted to the international normalised ratio (INR) 2-3. ${ }^{3}$ The ROCKET AF (Rivaroxaban versus Warfarin in Nonvalvular Atrial Fibrillation) trial was also a non-inferiority, randomised, double-blinded, controlled study that compared rivaroxaban $20 \mathrm{mg}$ daily $(15 \mathrm{mg}$ daily in patients with creatinine clearance [CrCl] 30-49 $\mathrm{mL} / \mathrm{min}$ ) with the warfarin dose adjusted to INR 2-3. ${ }^{4}$ The ARISTOTLE (Apixaban for Reduction in Stroke and Other Thromboembolic Events in Atrial Fibrillation) trial was similar in design, comparing apixaban (5 mg twice daily or $2.5 \mathrm{mg}$ twice daily in patients who have two out of three criteria [serum creatinine $>1.5 \mathrm{mg} / \mathrm{dL}$, weight $<60 \mathrm{~kg}$, age $>80$ years]) and warfarin. ${ }^{5}$ Lastly, the ENGAGE AF-TIMI 48 (Effective Anticoagulation With Factor Xa Next Generation in Atrial Fibrillation-Thrombolysis in Myocardial Infarction 48) trial, also similar in design, compared edoxaban $60 \mathrm{mg}$ daily (30 mg if $\mathrm{CrCl} 30-50 \mathrm{~mL} / \mathrm{min}$, weight $<60 \mathrm{~kg}$ or receiving concurrent verapamil or quinidine) with warfarin. ${ }^{6}$ All four studies enrolled patients with one or more risk factors for stroke. The mean CHADS2 score for patients was 2.1 for both the ARISTOTLE and RE-LY trials, but was slightly higher for patients in ROCKET AF (CHADS2 3.5) and

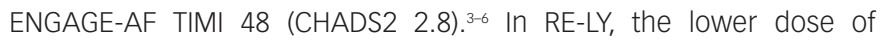
dabigatran was demonstrated to be non-inferior to warfarin for the primary endpoint of stroke or systemic embolism (SSE), while the higher dose was superior to warfarin. Incidence of haemorrhagic stroke was significantly lower for both of the dabigatran doses. ${ }^{3}$ In ROCKET AF, rivaroxaban was non-inferior to warfarin for the primary endpoint (prevention of SSE). ${ }^{4}$ A similar bleeding rate was observed with both rivaroxaban and warfarin. In the ARISTOTLE trial, apixaban significantly reduced the risk of SSE compared with warfarin. ${ }^{5}$ Rates of major and non-major clinically relevant bleeding were also significantly lower with apixaban compared with warfarin. ${ }^{5}$ In ENGAGE-AF TIMI 48, edoxaban was non-inferior to warfarin for prevention of SSE. ${ }^{6}$ The overall bleeding risk was similar to warfarin. ${ }^{6}$ Overall, compared with warfarin, the incidence of major bleeding was significantly lower for dabigatran $110 \mathrm{mg}$ twice daily and apixaban $5 \mathrm{mg}$ twice daily and similar for dabigatran $150 \mathrm{mg}$ twice daily, rivaroxaban $20 \mathrm{mg}$ once daily and edoxaban $30 \mathrm{mg}$ and $60 \mathrm{mg}$ daily. ${ }^{3-6}$ The annual rate of intracranial bleeding was significantly lower than with warfarin for all the DOACs.3-6 By contrast, gastrointestinal bleeding was significantly more frequent with dabigatran $150 \mathrm{mg}$ twice daily, rivaroxaban $20 \mathrm{mg}$ daily and edoxaban $60 \mathrm{mg}$ daily, but similar for dabigatran $110 \mathrm{mg}$ twice daily and apixaban $5 \mathrm{mg}$ twice daily.4-6 Edoxaban $30 \mathrm{mg}$ daily has a significantly lower incidence of gastrointestinal bleeding compared with warfarin. ${ }^{6}$ In addition, rates of life-threatening bleeding with dabigatran $110 \mathrm{mg}$ twice daily and $150 \mathrm{mg}$ twice daily and fatal bleeding with rivaroxaban $20 \mathrm{mg}$ daily and apixaban $5 \mathrm{mg}$ twice daily, as well as edoxaban $60 \mathrm{mg}$ and $30 \mathrm{mg}$ were all significantly lower compared with warfarin..$^{3-5}$ Therefore, in general, DOACs appeared to have at least similar bleeding risk to warfarin (if not lower for some major bleeding such as intracranial 
haemorrhage), except for gastrointestinal bleeding, where some DOACs may post a higher risk.

\section{Use in special populations \\ Use in patients with renal diseases}

In the first major phase III clinical trials of each of the DOACs, patients who had significant renal dysfunction were excluded from the rivaroxaban ( $\mathrm{CrCl}<30 \mathrm{~mL} / \mathrm{min}$ ), apixaban $(\mathrm{CrCl}<25 \mathrm{~mL} / \mathrm{min}$ ), dabigatran $(\mathrm{CrCl}<30 \mathrm{~mL} / \mathrm{min})$ and edoxaban $(\mathrm{CrCl}<30 \mathrm{~mL} / \mathrm{min})$ studies. $^{3-6}$

A post-hoc analysis of the RE-LY trial evaluated efficacy versus risk in patients with $\mathrm{CrCl}>80 \mathrm{~mL} / \mathrm{min}$ versus those who have $\mathrm{CrCl}$ 30-80 mL/min. Dabigatran $150 \mathrm{mg}$ twice daily dose was associated with a lower risk of thromboembolic events compared with warfarin among patients with $\mathrm{CrCl}<80 \mathrm{~mL} / \mathrm{min}$ but was non-inferior among patients with $\mathrm{CrCl} \geq 80 \mathrm{~mL} / \mathrm{min}$. There were no differences in terms of major bleeding in patients on dabigatran $150 \mathrm{mg}$ twice daily compared to warfarin in those who have $\mathrm{CrCl}<80 \mathrm{~mL} / \mathrm{min}$. However, in patients with $\mathrm{CrCl}>80 \mathrm{~mL} / \mathrm{min}$, dabigatran was associated with fewer major bleeding events. Compared with warfarin, dabigatran $150 \mathrm{mg}$ twice daily significantly reduced the risk of intracranial haemorrhage in patients with $\mathrm{CrCl}<80 \mathrm{~mL} / \mathrm{min}$, but not for those $>80 \mathrm{~mL} / \mathrm{min}$. Patients who received the $110 \mathrm{mg}$ twice daily dose of dabigatran was superior to warfarin in terms of major bleeding among patients with $\mathrm{CrCl}>50 \mathrm{~mL} / \mathrm{min}$, but no difference in patients with $\mathrm{CrCl}<50 \mathrm{~mL} / \mathrm{min}$. Between all subgroups, the $110 \mathrm{mg}$ twice daily dose of dabigatran was superior to warfarin with respect to intracranial haemorrhage. This overall indicates that dabigatran is at least as safe as warfarin in patients with renal dysfunction. In contrast with the RE-LY trial subgroup analyses, a retrospective analysis of a Medicare population found that patients with chronic kidney disease had a significantly increased risk of major haemorrhage if they were receiving dabigatran. ${ }^{29}$ The differences in results between these two studies may be explained by the different patient population sizes and characteristics (Medicare patient population is $>65$ years of age), as well as the use of a reduced dose of dabigatran $75 \mathrm{mg}$ twice daily in patients with $\mathrm{CrCl}<30 \mathrm{~mL} / \mathrm{min}$ in real life based on the FDA-approved prescribing information, which was a dose approved based on pharmacokinetics data and not officially evaluated in the RE-LY trial.

A sub-analysis of the ROCKET AF study comparing patients with moderate renal function ( $\mathrm{CrCl} 30-49 \mathrm{~mL} / \mathrm{min}$ ) who received an adjusted dose of $15 \mathrm{mg}$ rivaroxaban once daily to those receiving warfarin demonstrated no difference in thromboembolic outcomes and major bleeding. ${ }^{8}$ However, the risk of gastrointestinal bleeding with rivaroxaban was higher compared with warfarin for patients with impaired clearance ( $\mathrm{CrCl} 30-49 \mathrm{~mL} / \mathrm{min})$. This effect was not seen in patients with $\mathrm{CrCl}$ $\geq 50 \mathrm{~mL} / \mathrm{min}$. In the haemodialysis population of a post-marketing cohort (although not a population studied in the landmark trial), an increased risk of bleeding was observed in rivaroxaban patients compared with warfarin patients. ${ }^{30}$

In a post-hoc analysis of ARISTOTLE, apixaban was superior to warfarin with respect to thromboembolic outcomes in the subgroup of patients with $\mathrm{CrCl} 50-80 \mathrm{~mL} / \mathrm{min} .{ }^{9}$ Apixaban was associated with a significantly lower risk of major bleeding among patients with $\mathrm{CrCl}$ $\leq 50 \mathrm{~mL} / \mathrm{min}$ and $50-80 \mathrm{~mL} / \mathrm{min}$ compared with warfarin, but similar in those with $\mathrm{CrCl}>80 \mathrm{~mL} / \mathrm{min}$.

Similar post-hoc analyses of the ENGAGE-AF TIMI 48 study demonstrated that the rate of thromboembolic events in the edoxaban group increased as renal function improved. ${ }^{10}$ When the rate of thromboembolic events was analysed according to quintile of $\mathrm{CrCl}$, patients with $\mathrm{CrCl}$ 77.9-98.1 $\mathrm{mL} / \mathrm{min}$ and $>98.1 \mathrm{~mL} / \mathrm{min}$ who received edoxaban had a higher risk of thromboembolic events compared with warfarin patients. Bleeding rates were lower at all levels of $\mathrm{CrCl}$ with edoxaban compared with warfarin

Most recently, the use of DOACs in patients with end-stage renal diseases has been examined. Early data suggest, however, that off-label use of dabigatran and rivaroxaban in patients on dialysis is occurring in routine clinical practice and may be associated with adverse outcomes. ${ }^{30}$ However, based on pharmacokinetic data, the FDA approved an updated label that recommended standard-dose apixaban in patients on haemodialysis. ${ }^{31}$ A retrospective cohort study of 25,523 (2,351 apixaban; 23,172 warfarin) Medicare beneficiaries with end-stage kidney disease undergoing dialysis and AF who were receiving apixaban or warfarin were matched based on prognostic score and compared..$^{32}$ In matched cohorts, there was no difference in the risks of SSE between apixaban and warfarin (hazard ratio [HR], 0.88; 95\% confidence interval [Cl], 0.69-1.12), but apixaban was associated with a significantly lower risk of major bleeding (HR, 0.72; 95\% $\mathrm{Cl}, 0.59-0.87$ ). In sensitivity analyses, standard-dose apixaban (5 mg twice a day; $n=1,034$ ) was associated with significantly lower risks of SSE and death compared with either reduced-dose apixaban (2.5 mg twice a day; $\mathrm{n}=1,317$; HR, 0.61 ; $95 \% \mathrm{Cl}, 0.37-0.98$ for SSE; HR, 0.64; 95\% Cl, 0.45-0.92 for death) or warfarin ( $\mathrm{HR}, 0.64 ; 95 \% \mathrm{Cl}, 0.42-0.97 ; \mathrm{p}=0.04$ for SSE; HR, $0.63 ; 95 \% \mathrm{Cl}, 0.46-0.85$ for death). Thus, it appears that apixaban use in patients on dialysis may be associated with a lower risk of major bleeding compared with warfarin, with a standard $5 \mathrm{mg}$ twice daily dose also associated with reductions in thromboembolic and mortality risk.

\section{Patients with obesity}

The FDA conducted an analysis that compared the rates of adverse events among rivaroxaban and warfarin patients from ROCKET AF across three weight categories $\left(18.5-24.99 \mathrm{~kg} / \mathrm{m}^{2}, 25-29.99 \mathrm{~kg} / \mathrm{m}^{2}\right.$ and $\left.\geq 30 \mathrm{~kg} / \mathrm{m}^{2}\right){ }^{11}$ There was no statistical relationship between weight category and the rate of SSE. There are no published pharmacokinetic or clinical analyses of dabigatran in patients with weight extremes. In patients with body weight $\leq 60 \mathrm{~kg}$ (but age $<80$ years and serum creatinine $<1.5 \mathrm{mg} / \mathrm{dL}$ ) who received apixaban $5 \mathrm{mg}$ twice daily $(n=1,426)$, major bleeding was significantly reduced compared with warfarin-treated patients (HR, 0.6; 95\% Cl, 0.4-0.9).12

\section{Patients with concurrent valvular heart disease and prosthetic valves}

All four DOACs are currently only indicated for stroke prevention in non-valvular AF. Use of any of these agents in patients with a mechanical heart valve is contraindicated based on the RE-ALIGN (A Randomised, Phase II Study to Evaluate the sAfety and Pharmacokinetics of oraL dablGatran Etexilate in Patients After Heart Valve replacemeNt) study, in which patients with a mechanical heart valve were randomised to dabigatran versus warfarin. ${ }^{13}$ The trial was prematurely terminated due to an excess of thromboembolic and bleeding events in the dabigatran group. As the first four landmark DOAC trials were all supposed to evaluate patients with non-valvular AF, the use of DOACs in patients with valvular heart disease is also generally avoided due to lack of evidence. However, in a recent meta-analysis of RE-LY, ROCKET AF, ARISTOTLE and ENGAGE-AF, the use of DOACs in 13,574 patients with valvular heart disease (without mechanical valve replacement) enrolled in these four trials, were analysed. ${ }^{14}$ Overall results showed that DOACs versus warfarin reduced SSE $(\mathrm{HR}, 0.70 ; 95 \% \mathrm{Cl}, 0.60-0.82)$ and intracranial haemorrhage ( $\mathrm{HR}, 0.47 ; 95 \% \mathrm{Cl}, 0.24-0.92)$ in patients with $\mathrm{AF}$ and with valvular heart disease. Risk reduction of major bleeding and intracranial 
haemorrhage was mostly driven by apixaban, edoxaban and dabigatran (HR for major bleeding: 0.79 [95\% Cl, 0.69-0.91]; HR for intracranial haemorrhage: 0.33 [95\% Cl, 0.25-0.45]) but not rivaroxaban (HR for major bleeding: 1.56 [95\% Cl, 1.20-2.04]; HR for intracranial haemorrhage: 1.27 [95\% Cl, 0.77-2.10]). The investigators concluded that DOACs might be a reasonable alternative for patients with $\mathrm{AF}$ and valvular heart disease. However, prospective studies are needed to confirm this result.

\section{Stroke prevention peri-cardioversion}

Restoration of sinus rhythm with electrical cardioversion is a treatment option for AF. However, the peri-procedural risk of stroke is well established as thrombi hiding in the left atria may be dislodged during cardioversion. ${ }^{15}$ Current AF management guidelines recommend that therapeutic anticoagulation be used for at least 3 weeks prior to electrical cardioversion for AF with unknown duration or duration greater than 48 hours, and continued for a minimum of 4 weeks after cardioversion. ${ }^{33}$ Post-hoc analyses of patients undergoing cardioversion from the four major DOAC trials have demonstrated similar rates of thromboembolic events in patients receiving DOACs compared with warfarin. ${ }^{16-9}$ Two prospective studies also confirmed such findings. The X-VERT (Explore the Efficacy and Safety of Once-Daily Oral Rivaroxaban for the Prevention of Cardiovascular Events in Patients With Nonvalvular Atrial Fibrillation scheduled for Cardioversion) trial compared rivaroxaban $20 \mathrm{mg}$ daily to warfarin in patients undergoing cardioversion. The primary efficacy of stroke, transient ischaemic attack, peripheral embolism, myocardial infarction and cardiovascular death were similar between the two groups (0.51\% rivaroxaban, $1.02 \%$ warfarin [relative risk (RR) $0.50,95 \% \mathrm{Cl} 0.15-1.73]) .^{20}$ The ENSURE-AF (Edoxaban versus enoxaparin-warfarin in patients undergoing cardioversion of atrial fibrillation) trial compared the use of edoxaban $60 \mathrm{mg}$ daily to enoxaparin bridged to warfarin in patients undergoing cardioversion. The primary endpoint of thromboembolic events, myocardial infarction and cardiovascular death occurred in $1 \%$ in each group (RR $0.46,95 \% \mathrm{Cl}$ $0.12-1.43)$ with similar rates of major bleeding and non-major clinically relevant bleeding. ${ }^{21}$ Another currently ongoing study, EMANATE (A Phase Iv Trial To Assess The Effectiveness Of Apixaban Compared With Usual Care Anticoagulation In Subjects With Non-valvular Atrial Fibrillation Undergoing Cardioversion), is designed to evaluate the use of apixaban in patients with AF undergoing cardioversion. This study will further help to define the safety of apixaban use during cardioversion. ${ }^{22}$ These results, in addition to the data discussed above, will help establish the safety and efficacy profiles of DOACs compared with warfarin in anticoagulation before and after cardioversion. Due to the fast onset of action, DOACs may also potentially lead to shorter wait times to cardioversion compared with warfarin, since some patients may require a longer period of time to achieve therapeutic warfarin doses. Future studies should also evaluate if DOACs, in addition to a transoesophageal echocardiogram, can be utilised to facilitate cardioversion without patients having to receive therapeutic anticoagulation for 3-4 weeks before cardioversion.

\section{Use in catheter ablation}

Radiofrequency ablation is a treatment option for symptomatic AF failing treatment with antiarrhythmic agents. While radiofrequency ablation may restore normal sinus rhythm, risk of stroke is increased throughout the perioperative period. The current 2017 American College of Cardiology guidelines recommend that patients undergoing ablation should receive oral anticoagulation beforehand, uninterrupted throughout the procedure and up to 2 months after the procedure (Class I for warfarin, dabigatran and rivaroxaban; Class || for other DOACs). ${ }^{34}$ During the procedure, it is recommended that heparin be given titrated to an activated clotting time (ACT) >300 seconds. In VENTURE-AF (A Study Exploring Two Treatment Strategies in Patients With Atrial Fibrillation Who Undergo Catheter Ablation Therapy), efficacy of uninterrupted rivaroxaban and warfarin were compared in patients undergoing ablation. Rates of thromboembolic events and bleeding were similar. However, patients who were randomised to rivaroxaban compared with warfarin required more units of heparin (mean 13,871 units versus 10,964 units, $p<0.001$ ) to maintain a therapeutic ACT level. ${ }^{23}$ In the RE-CIRCUIT (Randomized Evaluation of Dabigatran Etexilate Compared to warfarIn in pulmonaRy Vein Ablation: Assessment of an Uninterrupted periproCedUral alnticoagulation sTrategy) trial, the investigators randomised patients undergoing catheter ablation to uninterrupted dabigatran versus warfarin therapy. Rates of thromboembolic events were equally low on both treatment arms, but the use of dabigatran was associated with significantly fewer bleeding events compared with warfarin during the procedure and up to 8 weeks after ablation $(1.6 \%$ versus $6.9 \%, p<0.001) .{ }^{24}$ Similar studies are currently underway for apixaban and edoxaban. Based on the current evidence, DOACs should generally be considered a safe and effective alternative to warfarin for stroke prevention during catheter ablation procedures.

\section{Use in patients after percutaneous coronary intervention}

Patients with AF who undergo $\mathrm{PCl}$ present specific challenges. Dual antiplatelet therapy (DAPT) with aspirin and a P2Y12 inhibitor are the standard regimen after coronary stent placement to prevent stent thrombosis. ${ }^{25}$ With DAPT added onto anticoagulant therapy with warfarin or a DOAC, while effective at reducing ischaemic stroke and cardiovascular events, this 'triple therapy' combination is associated with a significant increase in risk of bleeding. ${ }^{35}$ Studies have been performed to establish alternative antithrombotic strategy to maximise the cardioprotective effect while minimising the risk of bleeding. The WOEST (What is the Optimal antiplatElet \& Anticoagulant Therapy in Patients With Oral Anticoagulation and Coronary StenTing) trial demonstrated that eliminating aspirin from this regimen could reduce bleeding by approximately $60 \%$ with no increase in thrombotic events. ${ }^{36}$ The results of the PIONEER AF-PCl (Open-Label, Randomized, Controlled, Multicenter Study Exploring Two Treatment Strategies of Rivaroxaban and a Dose-Adjusted Oral Vitamin K Antagonist Treatment Strategy in Subjects with Atrial Fibrillation who Undergo Percutaneous Coronary Intervention) study showed that using a reduced rivaroxaban dose (15 mg daily) with a P2Y12 inhibitor or low-dose rivaroxaban (2.5 mg twice daily) and DAPT in patients with AF undergoing PCl, might achieve an optimal risk versus benefit ratio. Compared with triple therapy, lower rates of bleeding were seen in the $15 \mathrm{mg}$ rivaroxaban group ( $\mathrm{HR}, 0.59 ; 95 \% \mathrm{Cl}, 0.47-0.76 ; \mathrm{p}<0.001$ ) and $2.5 \mathrm{mg}$ twice-daily rivaroxaban group ( $\mathrm{HR}, 0.63 ; 95 \% \mathrm{Cl}, 0.50-0.80 ; \mathrm{p}<0.001)$, with similar rates of cardiovascular death, myocardial infarction and stroke. ${ }^{37}$ Similarly, the REDUAL (Evaluation of Dual Therapy With Dabigatran vs. Triple Therapy With Warfarin in Patients With AF That Undergo a PCI With Stenting) PCI trial showed that using a dabigatran- (110 mg twice daily and $150 \mathrm{mg}$ twice daily) based antithrombotic regimen with a P2Y12 inhibitor resulted in a lower incidence of bleeding with similar rates of thromboembolic events, death or urgent revascularisation. Compared with triple therapy, the bleeding risk was lower in both the $110 \mathrm{mg}$ twice daily dabigatran arm ( $\mathrm{HR}, 0.52 ; 95 \% \mathrm{Cl}, 0.42-0.63$; $\mathrm{p}<0.05)$ and $150 \mathrm{mg}$ twice daily dabigatran arms ( $\mathrm{HR}, 0.72 ; 95 \% \mathrm{Cl}$, 0.58-0.88; $p<0.05) .{ }^{38}$ Further studies are underway to explore the use of edoxaban- and apixaban-based antithrombotic regimens following PCI. ${ }^{39,40}$ The cumulative evidence across WOEST, PIONEER and 
RE-DUAL has not shown a significant difference in thromboembolic risk and recommends against the routine use of long-term triple therapy. The necessity of triple therapy will have to be considered based on individual thrombotic and bleeding risk. ${ }^{41}$

\section{Patients undergoing transcathetic aortic valve replacement}

Transcathetic aortic valve replacement (TAVR) is the treatment of choice for patients with severe aortic stenosis and intermediate-to-high operative risk. DAPT with aspirin and clopidogrel is currently the standard treatment post TAVR. However, a significant portion of patients undergoing TAVR also have AF and require chronic oral anticoagulation. Currently, data on the use of DOAC in this patient population are limited. In a prospective, non-randomised study, 617 patients undergoing TAVR received apixaban (if the procedure was performed in 2014) or warfarin (if the procedure was performed in 2013). ${ }^{26}$ Among patients with AF, 141 (51.8\%) were treated with apixaban and 131 (48.2\%) with a vitamin $\mathrm{K}$ antagonist. There was a significantly lower rate of the early safety endpoint (all-cause mortality, major vascular complications, ischaemic stroke [disabling and non-disabling] and bleeding complications) in patients with $\mathrm{AF}$ treated with apixaban compared with patients treated with a vitamin $\mathrm{K}$ antagonist (13.5\% versus $30.5 \% ; p<0.01$ ), with a numerically lower stroke rate $(2.1 \%$ versus $5.3 \% ; p=0.17)$ at 30 days and 12 months ( $1.2 \%$ versus $2.0 \% ; p=0.73$ ) of follow-up. Future larger-scale studies are needed to define the efficacy and safety of the use of DOAC in patients with AF undergoing TAVR.

\section{Reversal agents}

Despite their ease of use and lack of required therapeutic monitoring, during the early days when DOACs were available on the market, the lack of antidote or reversal agents was a major worry to clinicians and patients alike. Clinicians were concerned that unlike heparin or warfarin, which have specific reversal agents, major bleeding occurring during DOAC therapy would be hard to manage, especially in patients with renal dysfunction, which may prolong the half-life of the medications. ${ }^{42}$ If massive ingestion of a DOAC is suspected within the past 1-2 hours, activated charcoal can be used to reduce gastrointestinal absorption. ${ }^{43,44}$ Other supportive care, including mechanical compression of the bleeding site, fluid repletion, blood transfusion and administration of fresh frozen plasma can be initiated. For major bleeding with dabigatran, current American Heart Association guidelines recommend intravenous idarucizumab, a monoclonal antibody to dabigatran, at a dose of $5 \mathrm{~g}$ for the immediate reversal of the drug effect. ${ }^{44}$ The RE-VERSE AD (Reversal of Dabigatran Anticoagulant Effect With Idarucizumab) trial demonstrated that patients who received idarucizumab can have their thromboplastin time and ecarin clotting time normalised within minutes. ${ }^{45}$ Adexanat alfa, a recombinant modified human factor $x a$ decoy protein that is catalytically inactive but that retains the ability to bind factor Xa inhibitors in the active site with high affinity, has been approved as an antidote to factor Xa inhibitors, including rivaroxaban and apixaban. One study in patients receiving the two DOACs demonstrated that adexanet alfa reduced anti-Xa activity in apixaban patients by $100 \%$ and by $92 \%$ in rivaroxaban patients. ${ }^{46}$ In another study in patients who had major bleeding with rivaroxaban and apixaban, haemostasis was achieved in $79 \%$ of patients. However, thrombotic events occurred in $18 \%$ of patients in 30-day follow-up. ${ }^{47}$ The availability of reversal agents will ease some concern in clinical practitioners in terms of use of DOACs in patients who have a higher risk of bleeding.

\section{Conclusion}

With the results of the four landmark DOAC trials, direct thrombin inhibitor and factor $\mathrm{Xa}$ inhibitors have been established as safe and effective alternatives to warfarin for anticoagulation in non-valvular AF. Given their rapid onset of action, relatively simple dosing and no requirements for routine monitoring, this class of medications may allow a larger portion of patients with AF to be optimally anticoagulated. As their use becomes more prevalent, it is important to further examine the use of these agents in patients with AF who also have other high incidence co-morbidity, such as chronic kidney disease, valvular disease and prosthesis and coronary artery disease, especially those requiring $\mathrm{PCl}$. Overall, the results available to date suggest that DOACs are generally well tolerated across a wide spectrum of patients with $A F$, including those with mild-to-moderate renal dysfunction, obesity and valvular heart disease based on a post-hoc analysis of the original landmark trials. ${ }^{7-12}$ The use of DOACs in patients with a mechanical heart valve is not recommended due to an increase in thrombotic risk. The use of DOACs routinely in addition to DAPT increases bleeding risk; however, removal of aspirin from the regimen allows equivalent efficacy in terms of preventing cardiovascular events without increased risk of bleeding. Furthermore, patients with AF often require procedures, such as electrical cardioversion or catheter ablation. DOACs can be safely used around these procedures. Reversal agents are also now available should major bleeding occur; this will continue to expand the use of DOACs. Future research should continue to explore the use of DOACs in other special populations, such as obesity, pregnancy and in other coagulation disorders where warfarin is the current preferred agent. $\square$
1. Passman R, Bernstein RA. New appraisal of atrial fibrillation burden and stroke prevention. Stroke. 2016;47:570-6

2. You JJ, Singer DE, Howard PA, et al. Antithrombotic therapy for atrial fibrillation: Antithrombotic therapy and prevention of thrombosis, 9th ed: American College of Chest Physicians evidence-based clinical practice guidelines. Chest. 2012;141:e531S-75S.

3. Connolly SJ, Ezekowitz MD, Yusuf S, et al. Dabigatran versus warfarin in patients with atrial fibrillation. $N$ Engl I Med. 2009;361:1139-51.

4. Patel MR, Mahaffey KW, Garg J, et al. Rivaroxaban versus warfarin in nonvalvular atrial fibrillation. $N$ Eng/ I Med. 2011;365:883-91.

5. Granger $\mathrm{CB}$, Alexander $\mathrm{JH}, \mathrm{MCMurray} \mathrm{JJ}$, et al. Apixaban versus warfarin in patients with atrial fibrillation. $N$ Eng/ I Med. 2011;365:981-92.

6. Giugliano RP, Ruff $\mathrm{CT}$, Braunwald E, et al. Edoxaban versus warfarin in patients with atrial fibrillation. $N$ Eng/ I Med. 2013;369:2093-104

7. Hijazi Z, Hohnloser SH, Oldgren J, et al. Efficacy and safety of dabigatran compared with warfarin in relation to baseline rena function in patients with atrial fibrillation: a RE-LY (Randomized Evaluation of Long-term Anticoagulation Therapy) trial analysis. Circulation. 2014;129:961-70.

8. Fox KA, Piccini JP, Wojdyla D, et al. Prevention of stroke and systemic embolism with rivaroxaban compared with warfarin in patients with nonvalvular atrial fibrillation and moderate renal impairment. Eur Heart J. 2011;32:2387-94.

9. Hohnloser SH, Hijazi Z, Thomas L, et al. Efficacy of apixaban when compared with warfarin in relation to renal function in patients with atrial fibrillation: insights from the ARISTOTLE tria. Eur Heart J. 2012;33:2821-30.

10. Bohula EA, Giugliano RP, Ruff $C T$, et al. Impact of renal function on outcomes with edoxaban in the ENGAGE-AF TIMI 48 trial. Circulation. 2016;134:24-36.

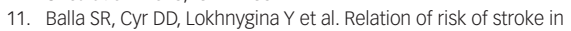
patients with atrial fibrillation to body mass index (from patients treated with rivaroxaban and warfarin in the rivaroxaban once daily oral direct factor $X a$ inhibition compared with vitamin $\mathrm{K}$ daily oral direct factor Xa inhibition compared with vitamin K
antagonism for prevention of stroke and embolism trial in atrial antagonism for prevention of stroke and embolis
fibrillation trial). Am J Cardiol. 2017:119:1989-96.

12. Alexander JH, Andersson U, Lopes RD, et al. Apixaban $5 \mathrm{mg}$ twice daily and clinical outcomes in patients with atrial fibrillation and advanced age, low body weight, or high creatinine: a secondary analysis of a randomized clinical trial. JAMA Cardiol. 2016;1:673-81.

13. Eikelboom JW, Connolly SJ, Brueckmann M, et al. Dabigatran versus warfarin in patients with mechanical heart valves. N Eng/ J Med. 2013;369:1206-14.

14. Pan $\mathrm{KL}$, Singer $\mathrm{DE}$, Ovbiagele $\mathrm{B}$, et al. Effects of non-vitamin $\mathrm{K}$ antagonist oral anticoagulants versus warfarin in patients with atrial fibrillation and valvular heart disease. A systematic review atrial fibrillation and valvular heart disease. A systematic rev
and meta-analysis. J Am Heart Assoc. 2017;6:e005835. doi: 10.1161/JAHA.117.005835.
15. Arnold AZ, Mich MJ, Mazurek RP, et al. Role of prophylactic anticoagulation for direct cardioversion in patients with atrial fibrillation or atrial flutter. J Am Coll Cardiol. 1992;19:851-5.

Piccini JP, Stevens ST, Lokhnygina Y, et al. Outcomes after cardioversion and atrial fibrillation ablation in patients treated with rivaroxaban and warfarin in the ROCKET AF trial. J Am Coll Cardiol. 2013;61:1998-2006.

17. Nagarakanti R, Ezekowitz MD, Oldgren J, et al. Dabigatran versus warfarin in patients with atrial fibrillation: an analysis of patients undergoing cardioversion. Circulation. 2011;123:131-6

18. Flaker G, Lopes RD, Al-Khatib SM, et al. Efficacy and safety of apixaban in patients after cardioversion for atrial fibrillation: insights from the ARISTOTLE trial (apixaban for reduction in stroke and other thromboembolic events in atrial fibrillation). J Am Coll Cardio. 2014;63:1082-7.

19. Plitt $A$, Ezekowitz MD, De Caterina R, et al. Cardioversion of atrial fibrillation in ENGAGE AF-TIMI 48. Clin Cardiol. 2016;39:345-6.

20. Cappato R, Ezekowtiz MD, Klein AL, et al. Rivaroxaban vs. vitamin $\mathrm{K}$ antagonists for cardioversion in atria fibrillation. Eur Heart J. 2014;35:3346-55

21. Goette Am Merino IL, Ezekowitz MD, et al. Edoxaban versus enoxaparin-warfarin in patients undergoing cardioversion of atrial fibrillation (ENSURE-AF): a randomized open-label, phase 3b trial. Lancet. 2016;388:1995-2003.

22. Ezekowitz MD, Pollack CV, Sanders P, et al. Apixaban compared 
with parenteral heparin and/or vitamin $\mathrm{K}$ antagonist in patients with nonvalvular atrial fibrillation undergoing cardioversion: rational and design of the EMANATE. Am Heart 2016;179:59-68.

23. Cappato R, Marchlinski FE, Hohnloser SH, et al. Uninterrupted rivaroxaban vs. uninterrupted vitamin $\mathrm{K}$ antagonists for catheter ablation in non-valvular atrial fibrillation. Eur Heart 2015;36:1805-11.

24. Calkins $\mathrm{H}$, Willems $\mathrm{S}$, Gerstenfeld EP, et al. Uninterrupted dabigatran versus warfarin for ablation in atrial fibrillation. N Engl J Med. 2177;376:1627-36.

25. Lip GYH, Windecker S, Huber K, et al. Management of antithrombotic therapy in atrial fibrillation patients antithrombotic therapy in atrial fibrillation patients
presenting with acute coronary syndrome and/or undergoing presenting with acute coronary syndrome and/or und
percutaneous coronary or valve interventions: a joint consensus document of the European Society of Cardiology Working Group. Eur Heart J. 2014;35:3155-79.

26. Seeger J, Gonska B, Rodewald C, et al. Apixaban in patients with atrial fibrillation after transfemoral aortic valve replacement. JACC Cardiovasc Interv. 2017;10:66-74.

27. Biase D, Callans D, Haeusler G, et al. Rationale and design of AXAFA-AFNET 5: an investigator-initiated, randomized, open, blind outcome assessment, multi-center trial to comparing continuous apixaban to vitamin $\mathrm{K}$ antagonists in patients undergoing atrial fibrillation catheter ablation. Europace. 2017;18:132-8.

28. Hohnloser SH, Camm J, Cappato R, et al. Uninterrupted administration of edoxaban vs vitamin $\mathrm{K}$ antagonists in patients undergoing atrial fibrillation catheter ablation: Rationale and design of the EUIMINATE-AF study. Clin Cardiol. 2018;41:440-9.

29. Hernandez I, Baik SH, Piñera A, et al. Risk of bleeding with dabigatran in atrial fibrillation. IAMA Intern Med. 2015;175:18-24

30. Chan KE, Edelman ER, Wenger JB, et al. Dabigatran and rivaroxaban use in atrial fibrillation patients on haemodialysis.
Circulation. 2015;131:972-9.

31. Bristol Myers Squibb Company. Eliquis $®$ (apixaban) Prescribing Information, 2012. Available at: https://packageinserts.bms com/pi/pi_eliquis.pdf (accessed 9 January 2019).

32. Konstantinos CS, Zhang X, Eckard A, et al. Outcomes associated with apixaban use in patients with end-stage kidney disease and atrial fibrillation in the United States. Circulation. 2018;138:1519-29.

33. January CT, Wann LS, Alpert JS, et al. 2014 AHA/ACC/HRS guideline for the management of patients with atrial fibrillation: a report of the American College of Cardiology/American Heart Association task force on practice guidelines and the Heart Rhythm Society. J Am Coll Cardiol. 2014;64:2246-80.

34. Calkins H, Hindricks G, Cappato R, et al. 2017 HRS/EHRA/ECAS/ APHRS/SOLAECE Expert Consensus Statement on catheter and surgical ablation of atrial fibrillation. Heart Rhythm. 2017;14:e275-444.

35. Lamberts M, Olesen JB, Ruwald MH, et al. Bleeding after initiation of multiple antithrombotic drugs, including triple therapy, in atrial fibrillation patients following myocardial infarction and coronary intervention: a nationwide cohort study. Circulation. 2012;126:1185-93.

36. Dewilde WJM, Oirbans T, Verheugt FWA, et al. Use of clopidogrel with or without aspirin in patients taking oral anticoagulant therapy and undergoing percutaneous coronary intervention: an open-label, randomized, controlled trial. Lancet. 2013;381:1107-15.

37. Gibson $\mathrm{CM}$, Mehran $\mathrm{R}$, Bode $\mathrm{C}$, et al. Prevention of bleeding in patients with atrial fibrillation undergoing PCI. N Eng/ J Med. 2016;375:2423-34.

38. Cannon CP, Bhatt DL, Oldgren J, et al. Dual antithrombotic therapy with dabigatran after $\mathrm{PCl}$ in atrial fibrillation N Engl J Med. 2017;377:1513-24.

39. NIH US National Library of Medicine. Apixaban vs phenprocoumon in patients with ACS and AF:
APPROACH-ACS-AF (APPROACH). 2018. Available at: https:// clinicaltrials.gov/ct2/show/NCT02789917 (accessed 10 December 2018)

40. NIH US National Library of Medicine. Edoxaban treatment versus vitamin $\mathrm{k}$ antagonist in patients with atrial fibrillation undergoing percutaneous coronary intervention (ENTRUST-AF-PCI).2018. Available at: https://clinicaltrials.gov/ ct2/show/NCT02866175 (accessed 10 December 2018).

41. Levine GN, Bates ER, Bittl JA, et al. 2016 ACC/AHA guideline focused update on duration of dual antiplatelet therapy in patients with coronary artery disease: a report of American College of Cardiology/American Heart Association Task Force on clinical practice guidelines. Circulation. 2016;137:e123-55.

42. Peacock WF, Rafique Z, Singer AJ. Direct-acting ora anticoagulants: Practical considerations for emergency medicine physicians. Emerg Med Int. 2016;2016:1781684.

43. Raval AN, Cigarroa JE, Chung MK, et al. Management of patients on non-vitamin $\mathrm{K}$ antagonist oral anticoagulants in the acute care and periprocedural setting: a scientific statement from the American Heart Association. Circulation. 2017; 137:e604-33.

44. Ruff CT, Giugliano RP, Antman EM. Management of bleeding with non-vitamin $\mathrm{K}$ antagonist oral anticoagulants in the era of specific reversal agents. Circulation. 2016;134:248-61.

45. Pollack CV, Reilly PA, Eikelboom J, et al. Idarucizumab for dabigatran reversal. N Eng/ J Med. 2015;373:511-20.

46. Siegal DM, Curnutte JT, Connolly SJ, et al. Adexanet alfa for the reversal of factor Xa inhibitor activity. $N$ Eng/ I $M$ Med. 2015;373:2413-24.

47. Connolly SJ, Milling TJ, Eikelboom JW, et al. Adexanet alfa for acute major bleeding associated with factor Xa inhibitors. N Eng/ J Med. 2016;375:1131-41. 